\title{
Use of Urinary PAH Metabolites to Assess PAH Exposure Intervention among Coke Oven Workers
}

\author{
Soo-Hun $\mathrm{CHO}^{1}$, Daehee Kang ${ }^{1}$, Jong-Won Kang ${ }^{1}$, Yeong-Su Ju${ }^{1}$, Joohon Sung', \\ Cheol-Koo LeE ${ }^{1}$, Song-Kwon LeE ${ }^{2}$, Young-Sei LeE ${ }^{2}$ and Paul T. Strickland ${ }^{3}$ \\ 'Department of Preventive Medicine, Seoul National University College of Medicine and Institute of \\ Environmental Medicine, SNUMRC, \\ ${ }^{2}$ Health Care Center, Pohang Iron \& Steel Company, \\ 'Division of Occupational and Environmental Health, Department of Environmental Health Sciences, \\ Johns Hopkins School of Hygiene and Public Health
}

\begin{abstract}
Use of Urinary PAH Metabolites to Assess PAH Exposure Intervention among Coke

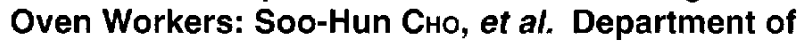
Preventive Medicine, Seoul National University College of Medicine and Institute of Environmental Medicine, SNUMRC-To assess the effectiveness of protective skin coveralls in reducing skin contamination among coke-oven workers, 1-hydroxypyrene glucuronide (1-OHPG) was used as an internal dose marker of polycyclic aromatic hydrocarbon (PAH) exposure. Twenty coke-oven workers at a steel plant in South Korea provided their first morning void urine samples before beginning work, as well as postshift urine samples after working for five days with regular skin protection. Pre- and postshift urine samples from the same workers were collected after new skin coveralls made from Tyvek ${ }^{\infty}$ had been worn during the week following regular skin protection. Urine samples were quantitated for 1-OHPG by immunoaffinity purification and HPLC with a fluorescence detector. The benzene-soluble fraction (BSF) of coke oven emissions (COE) in personal air samples from the 20 workers was also quantitated. To obtain information relating to smoking, job history, dietary habits, drug use, past medical history, and the use of personal protective equipment, a self-administered questionnaire was used. The mean age of study participants was $39.7 \mathrm{yr}$ and the average length of employment was 12 yr (11 months - $18 \mathrm{yr}$ ). In 20 workers, there was a statistically significant correlation between ambient COE and urinary 1-OHPG levels during the period of regular skin
\end{abstract}

Received Aug 17, 1999: Accepted March 4, 2000

Correspondence to: S.-H. Cho. Department of Preventive Medicine. Seoul National University' College of Medicine, 28 Yongon-Dong Chongno-Gu, Seoul, 110-799 KOREA

This Research was supported by Basic Medical Research Fund from the Ministry of Education, R.O.K. 1996. protection $(r=0.50, p<0.05)$. The difference in 1-OHPG levels between post- and preshift urine samples using regular skin protection was higher than when the new skin coveralls were worn. Although this was not statistically significant, there was a statistically significant difference in 1-OHPG among topside workers $(p<0.05)$. These results indicate that the introduction of the new skin coverall resulted in significant reductions of urinary PAH metabolites among workers exposed to higher levels of PAHs. The measurement of PAH metabolites in human urine appears to be ideally suited to biomonitoring in the workplace and testing the effectiveness of attempts to reduce $\mathrm{PAH}$ exposure.

(J Occup Health 2000; 42: 138-143)

Key words: Urinary PAH metabolites, Coke-oven workers, Intervention

Increased risk of lung cancer is associated with employment in the coke production areas of the steel industry ${ }^{1}$. The risk is believed to be due primarily to elevated air concentrations of polycyclic aromatic hydrocarbons (PAHs) found in this work environment ${ }^{2-4}$. A useful and direct approach to the assessment of human exposure and uptake of PAHs is to measure PAH metabolites excreted in urine ${ }^{5-10 !}$.

The measurement of PAH metabolites in human urine provides a means of assessing an individual's internal dose of PAHs ${ }^{11}$. A rapid assay for quantitation of 1 hydroxypyrene-glucuronide (1-OHPG) in human urine has been developed ${ }^{121}$. The assay has been applied in three validation studies of individuals with PAH exposure due to diet, occupation and/or smoking. Dietary exposure was examined in a controlled feeding study of charbroiled beef $f^{(3)}$. Occupational and smoking exposure was 
investigated in a study of steel plant workers and on-site controls $^{14}$. Smoking exposure was also examined in a study of smokers of blond or black tobacco ${ }^{15 !}$.

The development and institution of successful intervention to reduce PAH exposure levels in occupational settings requires evaluation of the methodologies involved, and a limited number of studies have examined the usefulness of urinary PAH metabolites for assessing the effect of such intervention ${ }^{16-18}$. The measures involved included new workwear policy (e.g. new coveralls, shirt, trousers, underwear, socks, and boots) and improved skin protection measures (e.g. washing the hands and face before a break, taking a shower after work, putting on new gloves and laundered work clothes) including special skin coveralls made from Tyvek $^{(*)}$. The effect of such intervention, as assessed by the reduction of urinary 1-hydroxypyrene (1-OHP) levels, ranged from $35 \%$ to $50 \%{ }^{16-18}$.

We recently conducted a study to evaluate several extra skin protective measures among 25 coke-oven workers at a steel plant in Korea ${ }^{(9)}$. First morning void urine samples of the 25 workers were collected before work, and postshift urine samples were collected after five days' work with regular skin protection. Pre- and postshift urine samples from the same workers were collected after several extra skin protective measures had been taken. These measures included: 1) encouraging washing the hands and face before each rest break; 2) the daily provision of clean work clothes; 3 ) the daily provision of new neck towels, gloves, and socks; 4) encouraging the use of clean underwear everyday; 5) the use of wristlets and skin protective creams. The results indicated that extra skin protective measures significantly reduced the excretion of PAH metabolites in coke oven workers by $31 \%$.

This study aimed to assess the effectiveness of reduced PAH exposure among coke-oven workers through the introduction of special skin coveralls made from Tyvek ${ }^{\text {(i) }}$. To this end, the usefulness of urinary PAH metabolites, 1-OHP and 1-OHPG, as internal dose markers of PAH exposure was evaluated.

\section{Materials and Methods}

\section{1) Study design and subjects}

On the basis of their job title, 20 coke-oven workers were recruited from a steel plant in South Korea. Eight were topside workers, eight were oven side workers, and four were maintenance workers. The mean age of study participants was $39.7 \mathrm{yr}$ and their length of employment at the plant averaged $12 \mathrm{yr}$ ( 11 months - $18 \mathrm{yr}$ ). It was reported that at the time of the study, $83 \%$ of participants were wearing protective respiratory equipment (Table 1 ). Seventy percent of subjects were current smokers and their average consumption was 12 pack-years and there were no significant differences in demographical
Table 1. General characteristics of study participants

\begin{tabular}{|c|c|c|}
\hline Variables & Mean & SD \\
\hline Age $(y r)$ & 39.7 & 5.2 \\
\hline Body surface area $\left(\mathrm{m}^{2}\right)$ & 1.8 & 0.1 \\
\hline Duration of employment (months) & 141.5 & 56.3 \\
\hline Smoking History (PY) & 11.7 & 6.3 \\
\hline Current smoker & \multicolumn{2}{|c|}{$70.0 \%$} \\
\hline Wearing Resp. PPE & \multicolumn{2}{|c|}{$83.3 \%$} \\
\hline
\end{tabular}

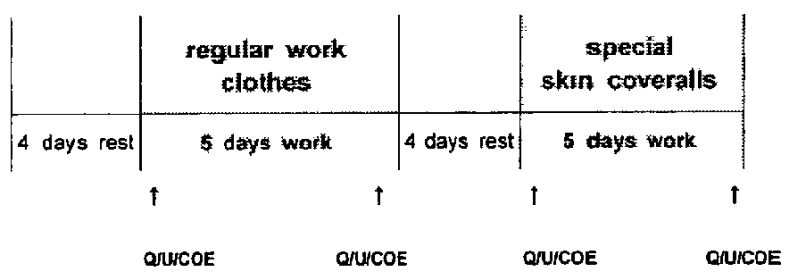

Fig. 1. Study design (Q/U/COE: questionnaire, urine collection, COE measurements).

characteristics among workers of different job titles.

First morning void urine samples were collected before work and postshift urine samples were collected after five days' work with regular skin protection. Pre- and postshift urine samples of the same workers were collected after new skin coveralls made from Tyvek ${ }^{(i)}$ (DuPont, USA) had been worn during the week following regular skin protection. Clothing made from Tyvek ${ }^{\circledR}$, a spun-bonded olefin sheet structure of $100 \%$ polyethylene, is known for its low permeability to particulates. Each worker had been provided with the skin coveralls everyday before they began to work. A self-administered questionnaire was used to obtain information about smoking habits, job history, major diseases, dietary habits, drug use, and the previous use of personal protective equipment. The design of the entire study is shown in Fig. 1.

\section{2) Urinary 1-hydroxypyrene glucuronide (1-OHPG) measurement}

Urine samples were quantitated for 1-OHPG by immunoaffinity purification and high performance liquid chromatography (HPLC) with a fluorescence detector, using a modification of the assay developed by Strickland et al. ${ }^{12)}$ To hydrolyze acid-labile metabolites, $2 \mathrm{~m} /$ urine samples were treated with $0.1 \mathrm{~N} \mathrm{HCl}\left(90^{\circ} \mathrm{C}\right)$. The hydrolyzed samples were loaded onto Sep-Pak $\mathrm{C}_{18}$ cartridges (Waters), washed with $30 \%$ methanol, and the relatively non-polar metabolites were eluted with $80 \%$ methanol. Concentrated samples were loaded into immunoaffinity columns (IAC) containing CNBractivated sepharose $4 \mathrm{~B}$ coupled with monoclonal antibody 
Table 2. COE concentration in different work places at the plant (1992-1995, unit: $\mathrm{mg} / \mathrm{m}^{3}$ )

\begin{tabular}{|c|c|c|c|}
\hline Year & Top side & Coke ovens & Maintenance sites \\
\hline Apr, 95 & $0.08(0.06-0.10)$ & $0.03(0.02-0.04)$ & $0.06(0.05-0.06)$ \\
\hline Sept, 94 & $0.06(0.05-0.08)$ & 0.02 (N.D-0.06) & 0.06 (N.D-0.09) \\
\hline Apr, 94 & $0.08(0.06-0.11)$ & $0.04(0.03-0.06)$ & $0.05(0.03-0.14)$ \\
\hline Sept, 93 & $0.08(0.05-0.15)$ & $0.05(0.02-0.07)$ & $0.03(0.01-0.06)$ \\
\hline Apr, 93 & $0.08(0.04-0.14)$ & 0.03 (N.D-0.05) & $0.04(0.01-0.06)$ \\
\hline Sept, 92 & $0.08(0.01-0.17)$ & $0.04(0.01-0.13)$ & 0.05 (N.D-0.14) \\
\hline
\end{tabular}

N.D =non-detectable

8E11 which recognizes several PAH adducts and metabolites ${ }^{20}$. Bound material was eluted with $40 \%$ methanol and eluated samples from the immunoaffinity columns were dried at $65^{\circ} \mathrm{C}$ in a vacuum and redissolved in $120 \mu l$ water. Each $20 \mu l$ of prepared samples was injected and analyzed by HPLC with a fluorescence detector (Waters gradient controller, Waters 515 pump, Waters 717 plus autosampler, Waters 474 scanning fluorescence detector and Autochro-Win chromatography data system, Young In, Korea). Gradient elution using methanol and water was carried out (10\% methanol for 5 $\min , 10-100 \%$ methanol for $25 \mathrm{~min}$ and $100 \%$ methanol for $10 \mathrm{~min}$ ) at a flow rate of $1 \mathrm{~m} / / \mathrm{min}$. The fluorescence detector was fixed as $\lambda_{\mathrm{ex}}=347 \mathrm{~nm}$ and $\lambda_{\mathrm{en}}=381 \mathrm{~nm}$.

\section{3) Urinary 1-hydroxypyrene (I-OHP) measurement}

Urinary 1-OHP concentration was measured by HPLC with a fluorescence detector. The method was slightly modified from that originally developed by Jongeneelen et al. ${ }^{7}$

\section{4) Coke-oven emission measurements}

Benzene soluble fractions (BSF) of coke oven emissions (COE) in personal air samples from the 20 workers were quantitated by the NIOSH analytical method No. 5506. Table 2 shows COE concentrations in different workplaces at the plant during the period 19921995.

\section{5) Statistical analysis}

According to the Shapiro-Wilks W statistic, 1-OHPG levels observed in this study were log-normally distributed, and a $\log$ transformed 1-OHPG concentration (LOGOHPG) was used for their further analysis. The correlation between log transformed COE (LOGCOE) and urinary LOGOHPG was assessed by Pearson's correlation analysis.

Differences in LOGOHPG between pre- and postshift urine samples (DLOGOHPG) were evaluated by paired $t$ test. DLOGOHPG when special skin coveralls were worn were compared with DLOGOHPG during regular skin protection by Student's t test. To further evaluate the effect of the introduction of the special skin coveralls on urinary DLOGOHPG, analysis of covariance (ANCOVA) was used, adjusting for LOGCOE and BMI as covariates by PC-SAS (Version 6.12). Finally, data of topside workers $(n=8)$ were separately analyzed to assess the protective effect of skin coveralls for the high exposure group. Simple comparison of DLOGOHPG (Wilcoxon's rank sum test) and ANCOVA adjustment for BMI was performed.

\section{Results}

There was a statistically significant correlation between concentrations of $1-\mathrm{OHP}$ and 1-OHPG in the same urine samples ( $r=0.65, p<0.0001$, Fig. 2). There was a statistically significant correlation between ambient $\mathrm{COE}$ and urinary 1-OHPG levels during the period of regular skin protection $(r=0.50, p<0.05$, data not shown).

The difference in 1-OHPG levels between post- and preshift urine samples with regular skin protection was higher than when the new skin coveralls were being worn (Fig. 3). Although the difference in 1-OHPG levels between post- and preshift urine samples using the new skin coverall $(1.8 \mu \mathrm{g} / \mathrm{g} \mathrm{Cr})$ was lower than when regular clothing was worn $(2.7 \mu \mathrm{g} / \mathrm{g} \mathrm{Cr})$, this difference was not statistically significant. Data analysis on the basis of job category showed that only among topside workers were 1-OHPG increments significantly lower when special skin coveralls were worn than during regular skin protection $(\mathrm{p}<0.05$, by Wilcoxon's rank sum test for log-transformed data; Table 3).

In order to assess the effect of special skin coveralls on urinary 1-OHPG levels, residuals were compared between the use of regular skin protection and the special skin coveralls. They were calculated using the regression model after adjusting COE levels and BMI (model: LOGOHPG $=b o+b 1 *($ LOGCOE $)+b 2 * B M I)$. Although urinary DLOGOHPG levels in all study participants were not significantly different for both simple and multivariate comparison (adjusting for LOGCOE and BMI), there were significant differences in topside workers between the regular and special coveralls periods for simple and 


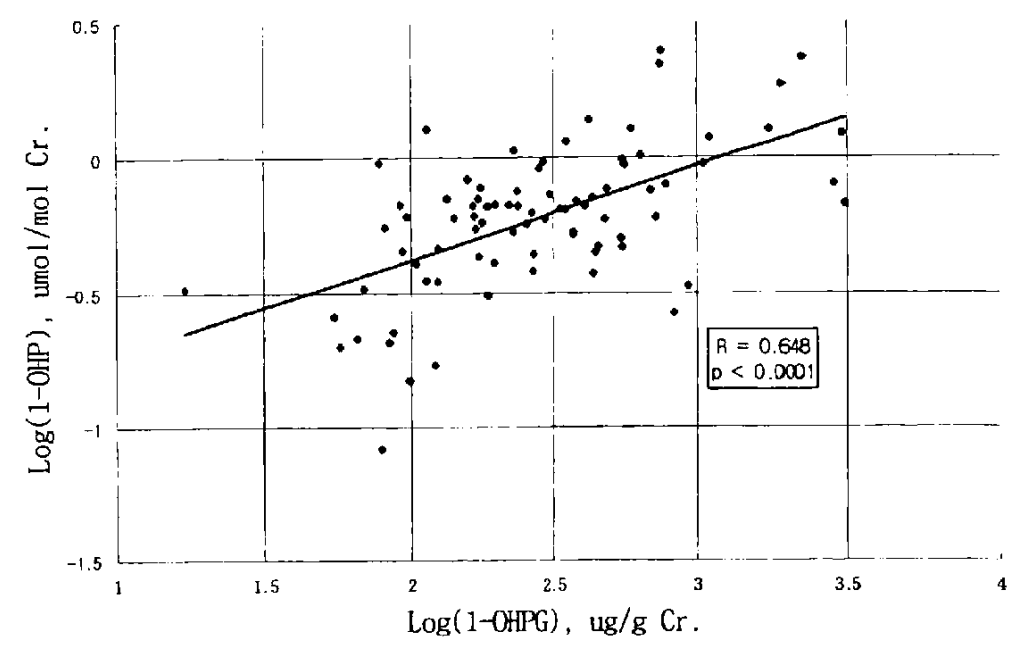

Fig. 2. Correlation between urinary 1-OHP and I-OHPG levels.

Table 3. COE and 1-OHPG differences according to job category

\begin{tabular}{|c|c|c|c|}
\hline \multicolumn{2}{|c|}{ GM (GSD) } & \multirow{2}{*}{$\frac{\text { Topside workers }(n=8)}{0.053(2.011)}$} & \multirow{2}{*}{$\frac{\text { Others }(\mathrm{n}=12)}{0.027(3.910)}$} \\
\hline $\mathrm{COE}\left(\mathrm{mg} / \mathrm{m}^{3}\right)$ & Ist pre: & & \\
\hline & Ist post: & $0.030(2.883)$ & $0.020(2.655)$ \\
\hline & 2nd pre: & $0.041(1.913)$ & $0.039(2.079)$ \\
\hline & 2nd post: & $0.045(3.001)$ & $0.029(2.975)$ \\
\hline \multicolumn{2}{|c|}{ increasing $1-\mathrm{OHPG}^{*}(\mu \mathrm{g} / \mathrm{g} \mathrm{Cr})$} & $3.006(0.002)$ & $1.605(0.004)$ \\
\hline \multicolumn{2}{|c|}{ increasing $1-\mathrm{OHPG}^{2}(\mu \mathrm{g} / \mathrm{g} \mathrm{Cr})$} & $2.203(0.003)$ & $1.591(0.005)$ \\
\hline
\end{tabular}

'During regular protection period. 2After the use of special skin coveralls. *p-value $<0.05$ (by Wilcoxon's rank sum test; $\log$-transformed data).

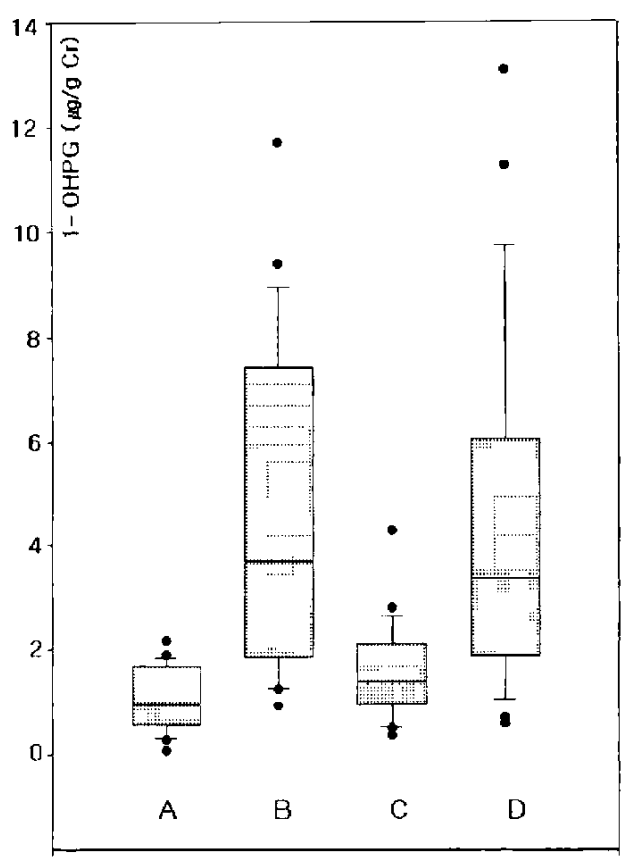

multivariate comparisons (adjusting for LOGCOE and BMI, p<0.05) (Fig. 4).

\section{Discussion}

In this study, we observed significantly reduced urinary 1-hydroxypyrene glucuronide (1-OHPG) excretion among topside workers exposed to higher levels of coke oven emissions (COE). Among all subjects, 1-OHPG increments during the use of special skin coveralls were lower than during the use of regular skin protection, though the significance disappears when residuals, calculated using the regression model of log-transformed

Fig. 3. Concentrations of urinary 1-OHPG.

A: preshift urine samples during regular clothing. B: postshift urine samples during regular clothing ( $\mathrm{p}^{-}$ value $<0.05$, by Wilcoxon's rank sum test between post- and preshift urine samples during regular skin protection). C: preshift urine samples during special skin coveralls. D: postshift urine samples during special skin coveralls. 


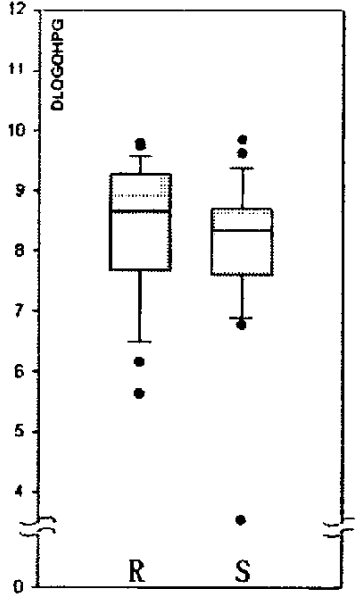

A

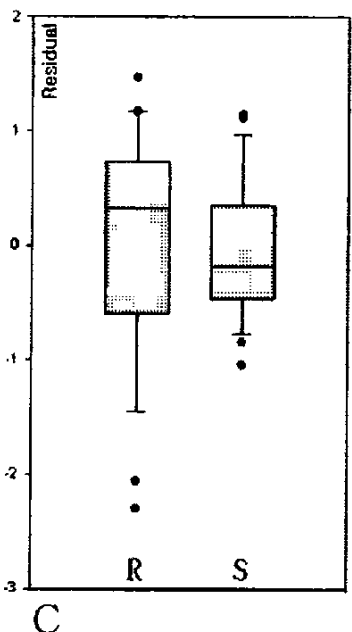

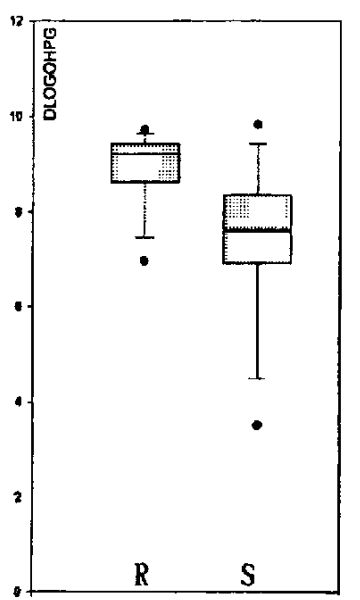

$\mathrm{B}$

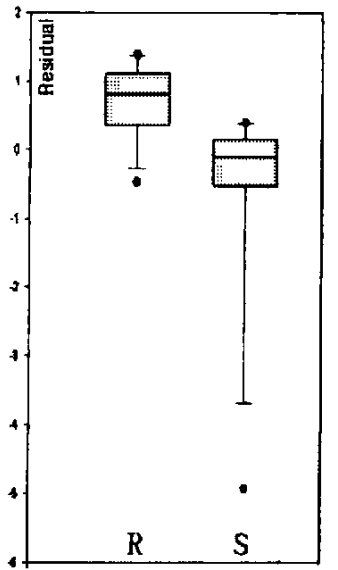

$\mathrm{D}$
Fig. 4. Comparison of the increment of urinary 1-OHPG level between regular clothing $(R)$ and special skin coverall period (S).

A: All workers ( $n=20$, DLOGOHPG: difference of log transformed 1-hydroxypyrene glucuronide between pre- and postshift samples). B: Topside workers only $(\mathrm{n}=8, \mathrm{p}<0.05$ by Wilcoxon's rank sum test). C: All workers ( $n=20$, Residual: calculated from ANCOVA model after adjusting for LOGCOE and BMI). D: Topside workers only $(n=8$, Residual after adjusting for LOGCOE and BMI, $\mathrm{p}=0.07$ by ANCOVA test, $\mathrm{p}=0.01$ by Wilcoxon's rank sum test).

1-OHPG (LOGOHPG) as a dependent variable, COE and body mass index (BMI) - which have shown significant association with LOGOHPG -, as independent variables, were compared between the use of regular skin protection and the use of the special skin coveralls. The findings observed in this study have various possible explanations: 1) due to small sample size, there was not enough statistical power to build a robust regression model; 2) in this model, most 1 -OHPG variation was not explained by COE, BMI, or the use of special skin coveralls, and incomplete adjustment of other confounders and individual differences in pyrene metabolism might thus affect 1 -OHPG levels ${ }^{(1)}$; 3 ) PAHs might penetrate the skin through uncovered areas; and 4) among these workers, skin absorption might not be the major route of exposure.

Since Van Rooij et $a l^{\left({ }^{(6)}\right)}$ first reported that in ten creosote-exposed workers, special skin coveralls reduced urinary $1-\mathrm{OHP}$ excretion by about $63 \%$, several studies assessed the effectiveness of intervention measures aimed at protecting workers from exposure to $\mathrm{PAHs}$, and the subsequent excretion of PAH metabolites. Quinlan $\boldsymbol{e t}$ $a l .{ }^{17}$ reported that among ten coal liquefaction workers, new workwear policy (new coverall, shirt, trousers, underwear, socks, and boots) significantly reduced 1-OHP excretion and deposition of PAHs on the skin. Van Rooij et al. ${ }^{18)}$ indicated that among 13 coke oven workers, simple hygienic skin protective measures (new gloves and laundered working clothes, washing both hands and face before each break) led to a $37 \%$ reduction in $1-\mathrm{OHP}$ excretion.

By measuring urinary PAH metabolites as markers of effectiveness, these studies show the significant effect of skin exposure reductior and also report that skin contamination is the main determinant of internal doses of PAHs exposure ${ }^{21.221}$. Several aspects of these reports need to be clarified, however, the first being inaccurate assessment of dermal and respiratory intake of PAHs. Because PAHs levels on a skin pad might not accurately reflect the exposure levels of natural skin, and also because the absorption rate constant used in the study was obtained from only four individuals, the extent to which PAHs entered via the skin might be overestimated. Second, because of variations in labor practices and the composition of PAHs in different job categories, the extent of reductions in skin exposure is affected, and intake varied according to the type of industry and occupation. This is born out by the findings of this study: a significant effect was seen only in topside workers. Finally, the rapidity and simplicity of the assay for 1-OHPG provides practical advantages in assessing the intervention effectiveness. Since 1-OHPG is approximately three- to five-fold more fluorescent than 1-OHP, it provides a more sensitive biomarker for assessing exposure to pyrene. However, concentration of urinary 1-OHP after deconjugation is correlated with 1-OHPG concentration in human urine, indicating that either assay can be used to determine human exposure to pyrene. The results of comparison of three different assays for 1-OHPG indicated that a simple and rapid method (fluorescence quantitation after immuno-affinity purification) shows reliable and comparable results to the assays using HPLC $^{23}$. This research clearly demonstrates, however, the usefulness of urinary PAH metabolites as markers for the effectiveness of exposure reduction programs in 
PAH exposed workers.

In conclusion, although the present study suffers from several limitations, including the absence of skin exposure monitoring, the use of a surrogate exposure indicator of specific PAH measurements, and small sample size, its findings indicate that the measurement of PAH metabolites in human urine appears to be ideally suited to biomonitoring in the workplace, and testing the intervention effectiveness of attempts to reduce PAH exposure.

\section{References}

1) Redmond CK, Ciocco A, Lloyd JW, Rush HW. Longterm mortality study of steelworkers: VI. Mortality from malignant neoplasms among coke oven workers. J Occup Med 1972; 14: 621-629.

2) Bjoseth A, Bjoseth O, Fjeldstad PE. Polycyclic aromatic hydrocarbons in the work atmosphere. II. Determination in a coke plant. Scand J Work Environ Health $1978 ; 4: 224-230$.

3) IARC. Monographs on the Evaluation of the Carcinogenic Risk of Chemicals to Humans: Polynuclear aromatic compounds, Part 1. IARC Monograph 32, 1983.

4) IARC. Monographs on the Evaluation of the Carcinogenic Risk of Chemicals to Humans: Polynuclear Aromatic Compounds, Part 3. IARC Monograph 34, 1984: 101-190.

5) Wu MT, Mao IF, Ho CK, et al. Urinary Ihydroxypyrene concentrations in coke oven workers. Occup Environ Med 1998; 55: 461-467.

6) Jongeneelen FJ. Methods for routine biological monitoring of carcinogenic PAH-mixtures. Sci Total Environ 1997; 199: 141-149.

7) Jongeneelen FJ, Anzion RBM, Henderson PT. Determination of hydroxylated metabolites of polycyclic aromatic hydrocarbons in urine. J Chromatography 1987; 413: 227-232.

8) Jongeneelen FJ, van Leeuwen FE, Oosterink S, et al. Ambient and biological monitoring of coke oven workers: determinants of the internal dose of polycyclic aromatic hydrocarbons. Br J Ind Med 1990; 47: 454 461.

9) Buchet JP, Gennart JP, Mercado-Calderon F, Delavignette JP, Cupers L, Lauwerys R. Evaluation of exposure to $\mathrm{PAH}$ in a coke production and graphite electrode manufacturing plant. Br J Ind Med 1992; 49 : 761-768.

10) Buckley TJ, Lioy PJ. An examination of the time course from human dietary exposure to polycyclic aromatic hydrocarbons to urinary elimination of 1 hydroxypyrene. Br J Ind Med 1992; 49: 113-124.

11) Strickland PT, Kang DH, Sithisarankul P. Urinary polycyclic aromatic hydrocarbon metabolites as biomarkers of exposure and effect. Environ Health Perspect 1996; 104 (Suppl 5): 927-932.

12) Strickland PT, Kang DH, Bowman ED, et al, Identification of 1-hydroxypyrene-glucuronide as a major metabolite in human urine by synchronous fluorescence spectroscopy and gas chromatography/ mass spectrometry. Carcinogenesis 1994; 15: 483-487.

13) Kang DH, Rothman $\mathrm{N}$, Poirier MC, et al. Interindividual differences in the concentration of 1 hydroxypyrene-glucuronide in urine and polycyclic aromatic hydrocarbon-DNA adducts in peripheral white blood cells after charbroiled beef consumption. Carcinogenesis 1995; 16: 1079-1085.

14) Kang DH, Rothman N, Cho SH, et al. Association of exposure to polycyclic aromatic hydrocarbon estimated from job category with concentration of 1 hydroxypyrene glucuronide in urine from steel plant workers. Occup Environ Med 1995; 52: 593-599.

15) Sithisarankul P, Vineis P, Kang DH, Rothman N, Caporaso N, Strickland PT. Association of 1hydroxypyrene glucuronide in human urine with cigarette smoking and broiled or roasted meat consumption. Biomarkers 1997; 2: 217-221.

16) Van Rooij JGM, Van Lieshout MAV, Bodelier-Bade $\mathrm{MM}$, Jongeneelen FJ. Effect of the reduction of skin contamination on the internal dose of creosote workers exposed to polycyclic aromatic hydrocarbons.Scand J Work Environ Health 1993; 19: 200-207.

17) Quinlan R, Kowalczyk G, Gardiner K, Calvert I. Exposure to polycyclic aromatic hydrocarbons in coal liquification workers: impact of a workwear policy on excretion of urinary 1-hydroxypyrene. Occup Environ Med 1995; 52: 600-605.

18) Van Rooij JGM, Bodelier-Bade MM, Hopmans PMJ, Jongeneelen FJ. Reduction of urinary 1-hydroxypyrene excretion in coke-oven workers exposed to polycyclic aromatic hydrocarbons due to improved hygienic skin protective measures. Ann Occup Hyg 1994; 38 : $247-$ 256.

19) Lec SK. A study for exposure assessment and improvement of health services concerning workers exposed to polycyclic aromatic hydrocarbons by using urinary metabolites. PhD thesis, Kyungsan University, 1996.

20) Santella RM, Lin CD, Cleveland WL, Weinstein IB. Monoclonal antibodies to DNA modified by a benzo[a]pyrene diol epoxide. Carcinogenesis 1984; 5 : 373-377.

21) Jongeneelen FJ, Scheepers PTJ, Groenendijk A, et al. Airborne concentrations, skin contamination, and urinary metabolite excretion of polycyclic aromatic hydrocarbons among paving workers exposed to coal tar derived road tars. Am Ind Hyg Assoc J 1988; 49; 600-607.

22) Moen BE, Nilsson R, Nordliner R, et al. Assessment of exposure to polycyclic aromatic hydrocarbons in engine rooms by measurement of urinary 1 hydroxypyrene. OEM 1996; 53; 692-696.

23) Lee CK, Cho SH, Kang JW, et al. Comparison of three analytical methods for 1-hydroxypyrene glucuronide in urine after non-occupational exposure to polycyclic aromatic hydrocarbons. Toxicology Letters 1999; 108; 209-216. 